\title{
Contribution to the biosystematic study of carpophoric basidiomycetes (higher fungi) in the Dakar region (Senegal)
}

\author{
Mamadou Sidybe, Modou Fall Gueye *, Sokhna Mboup, Ibou Diop, Mame Samba Mbaye * and Kandioura Noba \\ Botany - Biodiversity Laboratory, Department of Plant Biology, Faculty of Science and Technology, Cheikh Anta Diop \\ University, BP 5005, Dakar-Fann, Senegal.
}

GSC Biological and Pharmaceutical Sciences, 2021, 17(01), 052-060

Publication history: Received on 21 August 2021; revised on 29 September 2021; accepted on 01 October 2021

Article DOI: https://doi.org/10.30574/gscbps.2021.17.1.0289

\begin{abstract}
In Senegal, fungi constitute a large and diverse systematic group. However, despite their numerous food and pharmacological potential, few studies have been devoted to this group, particularly carpophore fungi. This work is a contribution to the knowledge of macromycetes in Senegal. It specifically proposes to determine the structure of the fungi on the prospected sites and to propose identification tools.

Inventories were made at four (4) sites: two sites in Cheikh Anta DIOP University of Dakar (Botanical Garden, Faculty of Science and Technology and that of Faculty of Medicine), the Forest Park of Hann and the classified forest of Mbao. The identification and description of the samples were carried out based on macroscopic and ecological characteristics. This methodology allowed us to identify (15) morphotypes distributed in 2 subclasses of the Basidiomycetes class. They belong to 5 orders (Agaricales, Pluteales, Trichlomatales, Phallales, Gasterales), 7 families (Agaricaceae, Lepiotaceae, Pluteaceae, Marasmiaceae, Termitomycetaceae, Phallaceae, Sclerodermataceae) and 8 genera. Among these morphotypes, four (4) are identified down to the species level (Phallus roseus, Podaxis pistillaris, Micropsalliota cf elata and Scleroderma auriculatum) and 11 down to the genus. In this fungi group, the genus Termitomyces dominates with five (5) species, followed by the genus Volvaria with three (3) species.

This work made it possible to bring out the common and differential characters between the species. It then appeared that the mode of insertion of the foot is the only characteristic common to all species. In addition, the identification of discriminating characteristics made it possible to develop a key for determining all the species inventoried.
\end{abstract}

Keywords: Mushroom fruiting body; Macroscopic; Ecological characteristics; Senegal

\section{Introduction}

Fungi are heterotrophic organisms once considered primitive or degenerate plants, devoid of chlorophyll. However, the only traits that fungi share with plants, apart from those common to all eukaryotes, are their immobile nature and their generally multicellular growth pattern [1]. Thus, fungi constitute a very diverse phylum of their own, comprised between plants and animals [2].

They colonize all terrestrial and aquatic environments and play a preponderant role in the ecology of the planet by contributing to the recycling of dead organic matter [3]. Currently, around 90,000 species of fungi have been described, whereas their number is estimated to be around 5 million [4].

\footnotetext{
${ }^{*}$ Corresponding author: Mamadou Sidybe, Modou Fall Gueye

Botany - Biodiversity Laboratory, Department of Plant Biology, Faculty of Science and Technology, Cheikh Anta Diop University, BP 5005, Dakar-Fann, Senegal. 
Fungi are of undeniable scientific and economic interest because of their biology [5] but also their modes of nutrition and life. In addition, the medicinal value of fungi is proven with their significant production of chemicals such as antibiotics [1].

In Africa, scientific knowledge on fungi is rather fragmentary. Scientific studies of macromycetes are especially important in central and eastern Africa [6]; [7]; [8]. In West Africa, studies are rare and have mainly focused on taxonomic, ethnomycological and mycosociological aspects [9]; [7], [8].

In Senegal, most studies on fungi have been done on mycorrhizal fungi and parasites of cultivated plants [10]. However, the systematic study of carpophore fungi has only gained renewed interest with the recent work of some authors [7]; [11]; [8]. It is important today to improve knowledge in these groups that play an important part in the biodiversity of Senegal. Thus the general objective of our study is to contribute to a better knowledge of carpophore fungi in Senegal and specifically, to know the structure and to propose tools for identifying the fungus of the prospected sites.

\section{Methodology}

\subsection{Presentation of study sites}

The study was carried out in the forest park of Hann, the botanical gardens of the Faculties of Science and Technology and Medicine of UCAD and the classified forest of Mbao.

The Hann forest and zoological park ( $\left.14^{\circ} 43^{\prime} 34^{~ " N o r t h ~ a n d ~} 17^{\circ} 26^{\prime} 02^{\prime \prime} \mathrm{W}\right)$ is located about 6 km from downtown Dakar, between the route des Pères Maristes, the route du Front of land and railways. It covers a total area of 60 ha. Today there are more than three hundred plant species and 134 animal species [11].

The Botanical Garden of the Faculty of Sciences and Techniques of UCAD was created in 1961 by Professor J. MIEGE and covers an area of 3 ha.

The Useful Plants Experimental Garden (JEPU) of the Pharmacognosy and Botany Laboratory (UCAD / Faculty of Medicine and Pharmacy) was created in 1986 and covers an area of approximately 1.9 ha.

The Mbao classified forest is located in the commune of Mbao (14 $4351 \mathrm{~N}$ and $\left.17^{\circ} 19^{\prime} 28^{\prime \prime} \mathrm{W}\right)$; Dakar region. The Mbao classified forest covers an area of 771 ha; it is mainly covered by plantations of Cashew trees, Eucalyptus and Filao.

\subsection{Harvesting and storing mushrooms}

The harvest was carried out between August and September, times favorable to the fungal growth in Senegal. The mushroom is placed on newspaper with a label bearing a number, the name of the harvester, the date and location of the harvest. The mushroom samples are sent to the laboratory and then dried in the sun (one day for the less fleshy mushrooms and two days for the more fleshy). Tiny or fragile mushrooms are immediately air dried to prevent destruction.

\subsection{Description of mushrooms}

The determination of higher fungi requires recognition of apparent characters. This description can be done with the naked eye or with a pocket magnifying glass. It is based on the analysis of the different parts of the fungus based on a set of characteristics concerning the cap, the foot, the partial and general veils and the flesh.

For the hat, the main identifying features were the shape, surface and coating, margin and diameter

Regarding the foot, observations focused on the foot-hat connection, the shape of the foot, the coating of the stipe, the weft (flesh) of the stipe, the base of the foot and the remains of the partial and general veils. Determining the characteristics of the mushroom's living environment (the substrate, the tree with which the fungus lives or is subservient, the biotope) is of paramount importance for their identification. The combination of macroscopic characters and ecological parameters makes it possible to name correctly a fungus [11]. 


\section{Results and discussion}

\subsection{Structure of the fungus}

During this work, 15 taxa were collected. They belong to 8 genera, 7 families distributed in 5 orders belonging to 2 subclasses of Holobasidiomycetes (Table 1). This number is far below that of [8] who described 82 taxa distributed in 41 genera and 23 families. These families were divided into 13 orders, 3 subclasses of the Homobasidiomycetes class of the Basidiomycotina sub-division. This difference in number and taxonomic diversity is related to the extent of the area surveyed by Kane. However, these results corroborate those of [11] who also described 7 species belonging to the order Agaricales. Also among the morphotypes collected:

- 4 morphotypes have been identified up to the species level, the 3 of which have already been encountered by [7]; they are Micropsalliota elata, Phallus roseus, podaxis Pistillaris and Scleroderma aruntium;

- 11 morphotypes are identified down to the genus level (Agaricus, Collybia, Termitomyces and Volvariella).

In this fungus, the genus Termitomyces is the most diverse with 5 taxa, followed by the genus Volvariella with 3 taxa and the genus Agaricus with 2 taxa (Table 1). The other genera are monospecific (Collybia, Micropsalliota, Phallus, Podaxis and Scleroderma). These results corroborate those of [8] with a predominance of the genera Agaricus and Termitomyces, with respectively 11 and 4 species. On the other hand, the genus Volvariella is represented by a single species. These results are also in line with those of [14]. In terms of generic diversity, these results are not in line with those of [18] because in his work it is the genera Scleroderma and Collybia that dominated in the Analamazaotra Forest Station. This dominance could be linked to ecological and climatic conditions such as temperature, precipitation, humidity and the nature of the substrate.

Among the families listed (Tables 1 and 4), that of the Agaricaceae is generically the most diverse with two genera. The other families are made up of one gender each. However, the family of Termitomycetaceae has the most important specific diversity followed by the family of Pluteaceae and that of Agaricaceae. The other families are represented by a genus and a species each (Lepiotaceae, Marasmiaceae, Phallaceae and Sclerodermataceae). The work of [10] also reports that Agaricaceae and Termitomycetaceae have very low generic diversity compared to other families. The Marasmiaceae, Lepiotaceae represent a relatively high generic diversity compared to the others. These results are similar to those obtained by [18] who noted a dominance of the Marasmiaceae family but low specific diversity in Agaricaceae. This low diversity noted in Agaricaceae was confirmed in the work of [11] on the study of Basidiomycetes species of the Agarical order in the Dakar region where only 7 species have been identified.

Among the orders encountered, the Tricholomatales are the most diverse with 2 families, 2 genera and 6 species (Table 3). The order of Agaricales also consists of 2 families and three genera, however, is less diverse than that of Tricholomatales since it contains only 4 species. The other orders contain only one family each. However, that of the Pluteales is more diverse than the others with 1 genus (Volvariella) and 3 species while the others (Gasterales and Phallales) contain only one genus and one species each. These results corroborate those of [8] where the Tricholomatales and the agarices remain the most diverse orders generically and specifically.

Among the two subclasses encountered, that of Agaricomycetideae is much more diverse with $60 \%$ of orders, about $71 \%$ of families, $75 \%$ of genera and nearly $87 \%$ of 15 species. These results are similar to those of [8] who had already reported in his work a predominance of Agaricomycetideae 
Table 1 Classification of taxa encountered

\begin{tabular}{|c|c|c|c|c|c|}
\hline Class & Subclass & Order & Family & Genus & Species \\
\hline \multirow{14}{*}{ Holobasidiomycetes } & \multirow{12}{*}{ Agaricomicetideae } & \multirow{4}{*}{ Agaricales } & \multirow{3}{*}{ Agaricaceae } & \multirow{2}{*}{ Agaricus } & $S p 1$ \\
\hline & & & & & $S p 2$ \\
\hline & & & & Micropsalliota & elata \\
\hline & & & Lepiodaceae & Podaxis & Pistillaris \\
\hline & & \multirow{3}{*}{ Pluteales } & \multirow{3}{*}{ Pluteaceae } & \multirow{3}{*}{ Volveriella } & Sp1 \\
\hline & & & & & $S p 2$ \\
\hline & & & & & Sp3 \\
\hline & & \multirow{5}{*}{ Trichomatales } & Marasmiaceae & Collybia & $S p$ \\
\hline & & & \multirow{4}{*}{ Termitomycetacae } & \multirow{4}{*}{ Termitomyces } & $S p 1$ \\
\hline & & & & & Sp2 \\
\hline & & & & & Sp3 \\
\hline & & & & & Sp4 \\
\hline & \multirow{2}{*}{ Gasteromycetideae } & Phalales & Phallaceae & Phallus & roseus \\
\hline & & Gastérales & Sclerodermataceae & Sleroderma & aurantium \\
\hline
\end{tabular}

Table 2 Structure of the fungus

\begin{tabular}{|l|c|c|c|c|c|c|c|c|}
\hline \multirow{2}{*}{ Subclass } & \multicolumn{2}{|l|}{ Orders } & \multicolumn{2}{l|}{ Family } & \multicolumn{2}{l|}{ Genus } & \multicolumn{2}{l|}{ Species } \\
\cline { 2 - 10 } & Number & $\mathbf{\%}$ & Number & $\mathbf{\%}$ & Number & $\mathbf{\%}$ & Number & \% \\
\hline Agaricomicetideae & 3 & 60 & 5 & 71.43 & 6 & 75 & 13 & 86.67 \\
\hline Gastéromycetideae & 2 & 40 & 2 & 28.27 & 2 & 25 & 2 & 13.33 \\
\hline Total & 5 & 100 & 7 & 100 & 8 & 100 & 15 & 100 \\
\hline
\end{tabular}

Table 3 The diversity of order

\begin{tabular}{|l|c|c|c|c|c|c|}
\hline \multirow{2}{*}{ Orders } & \multicolumn{2}{|c|}{ Family } & \multicolumn{2}{c|}{ Genus } & \multicolumn{2}{c|}{ Species } \\
\cline { 2 - 7 } & Number & \% & Number & \% & Number & $\%$ \\
\hline Agaricales & 2 & 28.57 & 3 & 37.5 & 4 & 26.67 \\
\hline Gasterales & 1 & 14.29 & 1 & 12.5 & 1 & 6.67 \\
\hline Phallales & 1 & 14.29 & 1 & 12.5 & 1 & 6.67 \\
\hline Pluteales & 1 & 14.29 & 1 & 12.5 & 3 & 20 \\
\hline Tricholomatales & 2 & 28.57 & 2 & 25 & 6 & 40 \\
\hline Total & 7 & 100 & 8 & 100 & 15 & 100 \\
\hline
\end{tabular}


Table 4 The diversity of families

\begin{tabular}{|l|c|c|c|c|}
\hline \multirow{2}{*}{ Family } & \multicolumn{2}{|l|}{ Genus } & \multicolumn{2}{l|}{ Species } \\
\cline { 2 - 5 } & Number & $\mathbf{\%}$ & Number & $\%$ \\
\hline Agaricaceae & 2 & 25 & 3 & 20 \\
\hline Lepiotaceae & 1 & 12.5 & 1 & 6.67 \\
\hline Marasmiaceae & 1 & 12.5 & 1 & 6.67 \\
\hline Phallaceae & 1 & 12.5 & 1 & 6.67 \\
\hline Pluteaceae & 1 & 12.5 & 3 & 20 \\
\hline Sclerodermataceae & 1 & 12.5 & 1 & 6.67 \\
\hline Termitomycetaceae & 1 & 12.5 & 5 & 33.33 \\
\hline Total & 8 & 100 & 15 & 100 \\
\hline
\end{tabular}

\subsection{Identification of taxa}

To facilitate the identification of the species, a morphological description and a determination key were produced.

There are common characters and differential characters.

The mode of insertion of the foot is the only characteristic common to all species. Others vary depending on the species.

The shape of the hat is very variable. It is circular in Agaricus sp2, circular with a flattened and concave profile at maturity in Micropsalliota elata, circular weakly mammillated with fissured margin in Termitomyces sp1, circular with a conical and hummed profile in Termitomyces sp2, circular flattened and nippled in Termitomyces sp3, circular, convex and pointed nipple in Termitomyces sp4, circular concave in Termitomyces sp5 and circular nipple in Volvariella sp2. However, some species of the genus Agaricus can have very variable caps, such as Agaricus essettei Bon, Agaricus sylvaticus Schaeff. Presenting respectively a campanulate then convex and finally plano-convex cap and a hemispherical cap [13]. These different hat shapes have been reported in the work of [13] on the microscopic and macroscopic description of Agaricus subsaharianus with a hat, globular, then plano-convex with a center sometimes slightly depressed. In termitomyces the caps are generally circular, nippled and sometimes conical in Termitomyces aurantiacus and T. striatus [10].According to [6], [8] the shape of the hat (in top and side view) is also very variable (circular; flabelliform; spatuliform; kidney-shaped; subglobular; parabolic; campanulate; conical; hemispherical; convex; umbonate; depressed; concave; umbilicus; infundibuliform). It is the same for the diameter of the cap which varies according to the stage of development of the species and the ecological conditions in which it is found.

The color of the hat is also variable. It is clear in some species, white in Agaricus sp2, whitish in Volveriella sp3 and Micropsalliota elata, cream-white in Podaxis pistillaris, whitish to beige in Volvariella sp1, beige in Termitomyces sp1, yellow in Termitomyces sp5, yellowish in Volveriella sp2 and Scleroderma aurantium. It can be dark in some species. It is black in Phallus roseus, gray in Termitomyces; gray-brown in Agaricus sp1 and bright brown in Collybia sp.

The surface of the hat presents a significant variation according to the species. It is smooth in Collybia sp and Termitomyces sp1, rimous in Termitomyces sp2 and Termitomyces sp5, fibrillous in Termitomyces sp4, Volveriella sp2, Squamous in Agaricus sp1, fluffy in Agaricus sp2, soft in Micropsalliota elata, alveolate in Phallus rosucheus and peluchus Podaxis pistillaris, rough and finely scaly in Scleroderma aurantium, veined, silky and felted in Volvariella sp1, striped in Termitomyces sp3, viscous and shiny in Volveriella sp3. It is therefore common ground that the color and appearance of the surface of the hat are also discriminating characteristics but vary depending on the taxa. These results corroborate those of [11], [8] and [13] during studies carried out on macroscopic fungi of the genus Agaricus from the Dakar region, on the biosystematics of carpophore fungi from Senegal and on eight fungal species of the genus Agaricus including three new for Morocco: Agaricus bresadolanus, a. campestris var. pilatianus and a. praeclaresquamosus.

The insertion of the foot is central in all species. However, the shape varies according to the species. It is cylindrical in Agaricus sp2, Collybia sp, Micropsalliota elata, Termitomyces and Scleroderma aurantium. It is cylindrical and straight in Podaxis pistillaris, radicating cylindrical in Agaricus sp1, Spatuliforme in Phallus roseus, cylindrical and curved downwards in Termitomyces sp3, cylindrical with bulbous base in Volveriella sp3, cylindrical slightly curved with 
swollen base and sometimes bulbous in Volveriella sp2, cylindrical narrower at the top and bulbous at the base in Volvariella sp1.

The color of the foot is also variable. It is white in Agaricus sp2, Termitomyces, Volveriella sp2, Volveriella sp3 and Micropsalliota elata, whitish in Volvariella sp1, white turning pink to the affected in Agaricus sp1, yellowish in Termitomyces sp5, Termitomyces sp4 and Podaxis pistillaris, reddish yellow under the cap and the remainder reddish in Collybia sp, pink in Phallus roseus and gray in Scleroderma aurantium.

From the point of view of ornamentation of the foot, the species Agaricus sp2, Agaricus sp1, Volveriella sp3, Termitomyces sp1 are hairless. The ornamentation is smooth and viscous in Volveriella sp2, Collybia sp, smooth and broadly striated in Termitomyces sp4, mottled in Phallus roseus, Micropsalliota elata, pruinose or subchinate in Volvariella sp1. It is striped in Termitomyces sp2, Termitomyces sp3, scaly in Scleroderma aurantium fibrillous in Podaxis pistillaris and rimous in Termitomyces sp5.

Foot length can vary from 1 to $2 \mathrm{~cm}$ in Scleroderma aurantium up to $27 \mathrm{~cm}$ in Termitomyces sp5. Characterizing only species of the genus volveriella, the volva exhibit several characteristics. It is divided into whitish or grayish lobes in Volvariella sp1, Ample, quite tall, very sheathing, persistent, brownish and not very scaly in Volveriella sp2, white, membranous, soft, lobed and sheathing in the species of the genus Phallus. Also, a variation in the coloration of the foot depending on the stage of development of the species was also observed. According to the results obtained, the insertion, shape, color, length and ornamentation of the foot are essential characteristics for the discrimination of certain groups of carpophore fungi. These observations were confirmed by the work of [16], [17], [12], [6]. These results also corroborate those of [11], [8] and [13].

The hymenophore is generally external with the exception of three species (Scleroderma aurantium, Phallus roseus, Podaxis pistillaris) in which it is internal. These observations corroborate those of [11], [8] and [13]. The hymenophore insertion is free in the species of the genus Volvariella and Agaricus, subliber in Micropsalliota elata, subliber in free in Termitomyces and emarginate Collybia sp. The blades are mostly clear. However, they can be white, whitish, yellow, pink, reddish yellow and not very dark in some species. The hymenophre type, the color and the hymenophore insertion at the foot are very variable according to taxonomic groups and particularly between Volvariella, Agaricus, Micropsalliota elata, Termitomyces and Collybia sp. These results corroborate those of [11], [15].

Macroscopic characterization of fungi is essential to determine it from carpophore fungi.

\subsection{Key to determining the species encountered}

Mushrooms with a bladed cap volva at the base of the foot ..Volvaire

Mushrooms with a whitish and / or beige cap

Mushrooms with a circular cap whose diameter is between 5 and $14 \mathrm{~cm}$; veined, silky and felted surface; volva lobed, sheathing whitish in color; cylindrical foot bulbous at the base and centrally inserted; hymenophore whitish to pink; eroded free blades these fungi grow on an environment very rich in humus (plant debris).

Volveriella sp1

4'- Campanulate hat mushrooms with a diameter of between 8 and $12 \mathrm{~cm}$, with a shiny surface to dry and viscous when wet; volva lobed, whitish, sheathing, soft and membranous; stipe cylindrical bulbous at the base; brownish pink hymenophore; single blades with regular edges; they grow on an environment very rich in humus (plant debris).

...Volveriella sp3

3'- Yellow-hatched, ovoid-shaped mushrooms with a fibrous, shiny, ocher surface; volva is lobed, sheathing, fairly tall whitish; stipe cylindrical, curved, slender and smooth; hymenophore whitish then pink and brownish; simple, regularedged blades; they were found in the hollows of senescent trees .. Volveriella sp2

2'- No volva at the base of the foot

5- Ring around the foot

6- Free blades Agaricus 
7- Root-foot fungus (foot terminated by a pseudo root or sclerotia), cap globular, hemispherical, convex then spreading, white color, surface adorned with gray-brown scales, cylindrical foot of reddening flesh when cut, surrounded by 'a membranous ring. Agaricus sp

7'- White-colored non-radicating foot fungi with a fluffy cap ornamentation, white stipe of cylindrical shape surrounded by a superior descending ring, with rhizomorphic base, hymenophore of pink or brown color, blades are simple, with free insertion and with regular ridges. Agaricus sp

6' - Subliber blades Micropsalliota

Fungus with white cap when juvenile, then brown-brown when adult, circular, concave in shape; cylindrical foot, with central insertion and mottled ornamentation; the blades are blackish-brown with subliberate insertion and regular ridges ..Micropsalliota elata

5 '- No ring around the foo

8- Subliber to free blades Termitomyces

9- Mushroom whose cap color is beige.

Circular hat; fibrous white flesh; cylindrical, bulbous foot with striped ornamentation; hymenophore is white; single blades with free subliber insertion and regular edge Termitomyces sp1

9'- Gray or yellow cap mushroom

10- Gray-cap mushroom

11- Mushroom whose hat ornamentation is granular, concave in shape; white and fibrous flesh; cylindrical foot with rhyming ornamentation; hypogea $27 \mathrm{~cm}$ long, hymenophore yellowish in color; free blades with regular edge. Termitomyces sp5

11 '- Mushroom with cracked or rhyming ornamentation on the hat.

12- Mushroom whose hat ornamentation is rhyming, fibrillous white flesh, slightly nippled and flattened in shape; with very broadly fissured margin; cylindrical stipe with striped ornamentation; white hymenophore; simple, free blades with a regular edge. Termitomyces sp2

12'- Mushroom with cracked hat ornamentation, flattened and weakly mammoth, fibrillous white flesh; cylindrical, bulbous foot with central insertion and striped ornamentation; white hymenophore; simple blades, subliber a free and with a regular edge. ..Termitomyces sp3

10- Mushroom of yellow color, with yellowish and fibrous flesh; hat with pointed nipple, convex and circular in shape, with a fibrous surface. Cylindrical foot, bulbous at its base; The yellowish hymenophore; simple blades, subliber, free and with a regular edge. Termitomyces sp4

8'- notched blades Collybia

Mushroom with a honey-pale bicolor cap towards the margin, bright brown in the center, slightly flattened convex shape with smooth and viscous ornamentation; foot with eccentric insertion sometimes central, bicolor yellow-whitish under the cap the remainder reddish; blades forked, adnate and with a regular ridge Collybia sp.

\section{1 '- Mushrooms with a cap without blades}

13- Volva at the base of the foot

.Phallus

Mushroom with blackish cap, circular, entirely welded to the foot with granular ornamentation; foot with central insertion, spatuliform, slender, slender, fragile and hollow, with honeycomb ornamentation with volva at its base of the same color as it; internal hymenophore... ..Phallus roseus 
13'- Without volva at the base of the foot

14- Ovoid cap Podaxis

The color of the fungus is uniform creamy white; the cap narrowly elliptical in shape, with a rounded top with fibrous and fluffy ornamentation; right cylindrical foot, with fibrillous and striated ornamentation; dense gleba, white when juvenile and blackish when ripe and powdery Podaxis pistillaris

14'- Gastroid hat Scleroderma

The fungus yellowish in color; the globular cap with a thick, rough and scaly surface as well as that of the foot; foot reduced to a pseudo-foot, extended by radicating mycelial cords; gleba brown in color becoming blackish-purplish and powdery when ripe Scleroderma aurantium

\section{Conclusion}

This study made it possible to take stock of current knowledge of the mycological flora of Senegal, in particular that of the Dakar region. This work allowed us to inventory about fifteen morphotypes divided into two subclasses. The subclass of Agaricomycetideae is more diverse with $60 \%$ of orders, about $71 \%$ of families, $75 \%$ of genera and nearly $87 \%$ of species while that of Gasteromycetideae is less diverse with $40 \%$ of orders, $28.57 \%$ families, $25 \%$ of genders and about $13.33 \%$.

In this fungus, the genus Termitomyces is the most represented with 5 morphotypes, followed by Volvariella with 3 taxa and Agaricus with 2 taxa. The other five genera are monospecific. All the species belong to 5 orders divided into 2 subclasses arranged in 7 families which are united in 8 genera.

The macroscopic and ecological characterizations of the fungi have made it possible to highlight the common and differential characters of the different taxa. On the basis of this characterization, a morphological description and a determination key were developed, to facilitate the identification of the 15 morphotypes encountered. Among the species encountered, all the Termitomyces listed are edible.

\section{Compliance with ethical standards}

\section{Acknowledgments}

The authors thank the producers, in the Niayes area and the Botany biodiversity laboratory.

\section{Disclosure of conflict of interest}

The authors declare no conflict of interest.

\section{References}

[1] Raven PH, Evert RF, Eichhorn S. Plant biology De Boeck \& Larcier s.a., Paris, Buxelles: De Boeck Université. 2000.

[2] Deysson G, Delcourt A. Cryptogamy: general and applied mycology. Paris: SEDES CDU. 1980.

[3] Pichard G, Rolland G. Fungi, essential elements in the forest ecosystem; France. 8; 2006.

[4] Knudsen H, Petersen JH. Mushrooms in nature, Delachaux and Niestlé SA, Paris. 2005; 306.

[5] Ozenda P. Plant organisms. 1. Inferior plants. Masson. 1990.

[6] Eyi Ndong H.C. Study of the fungi of the dense humid forest consumed by the populations of northern Gabon. Doctoral thesis, Université libre de Bruxelle. 271; 2009.

[7] Kane M. Contribution to the systematic study of carpophore fungi in the Cape Verde peninsula.Master's Thesis (DEA) in Plant Biology / Cheikh Anta Diop University of Dakar. 2006; 108.

[8] Kane M. Contribution to the systematic study of higher sporophore fungi from Senegal. Unique doctoral thesis. Cheikh Anta Diop University of Dakar. 2014; 307. 
[9] Guissou K. M. L. The Macromycetes of Burkina Fasso: Inventory, Ethnomycology, Nutritional and Therapeutic Values of some species. 3rd cycle doctoral thesis. University of Ouagadougou. 2005; 186.

[10] Kane A, Ducousso M, Mbaye MS, Noba K, Ba AT, Dreyfus B. Diversity of arbuscular mycorrhizal (AM) fungi associated with millet and peanuts in Senegal. 11th Congress of the African Association on Biological Nitrogen Fixation (AABNF), Dakar, Senegal. 2004

[11] Ngom K. Contribution to the knowledge of fungal biodiversity in Senegal by a study of Basidiomycetes species of the order of Agaricales in the Dakar region. Master thesis. Cheikh Anta Diop University. 2012; 43.

[12] Bâ A. M., Duponnois R., Diabaté M. Dreyfus B. Ectomycorrhizal fungi of forest trees in West Africa: Study methods, diversity, ecology, use in forestry and edibility. IRD edition. 2011; 268.

[13] El kholfy S, El-assfouri A, Belahbib N, Touhami AO, Benkirane R, Douira A. Study of eight fungal species of the genus Agaricus including three new for Morocco: Agaricus bresadolanus, A. campestris var. pilatianus and A. praeclaresquamosus. Bulletin of the Scientific Institute, Rabat, Life Sciences section. 2007; 33(2): 47-52.

[14] Ibrahim D, Hama O, Daniels PP, Inoussa MM, Barage M, Adam T, Infante F. Diversity of basidiomycete carpophoric fungi subservient to certain species of Caesalpiniaceae of the W National Park of Niger (West Africa). Journal of Applied Biosciences. 2017; 116: 11566-11576.

[15] Ndong, H. E., Degreef, J., \& De Kesel, A. Edible fungi of the dense forests of Central Africa. Taxonomy and identification. Belgian Development Cooperation. 2011; 262.

[16] Roger P. Fungi. Edition Solar, Paris. 1981; 288.

[17] Romagnesi H. Atlas of European mushrooms. Ed. Bordas, Paris. 1995; 290. 